\title{
Effects of DKK1 overexpression on bone metastasis of SBC-3 cells
}

\author{
HAILIN PANG ${ }^{1 *}$, NINGQIANG MA ${ }^{1 *}$, WEIWEI SHEN ${ }^{1}$, QIANG ZHAO $^{2}$, JIANLIN WANG $^{3}$, \\ LIAN DUAN $^{1}$, WENJUAN CHEN ${ }^{1}$, NING ZHANG ${ }^{1}$, ZHENGWEI ZHAO $^{4}$, LILI LIU $^{1}$ and HELONG ZHANG ${ }^{1}$ \\ ${ }^{1}$ Department of Oncology, Tangdu Hospital, The Fourth Military Medical University, Xi'an, Shaanxi 710038; \\ ${ }^{2}$ Department of Oncology, The Third Hospital of PLA, Baoji, Shaanxi $721004 ;{ }^{3}$ Department of Hepatobiliary Surgery, \\ Xijing Hospital, The Fourth Military Medical University, Xi'an, Shaanxi 710032; ${ }^{4}$ Department of Thoracic Surgery, \\ Tangdu Hospital, The Fourth Military Medical University, Xi'an, Shaanxi 710038, P.R. China
}

Received April 16, 2017; Accepted January 19, 2018

DOI: $10.3892 / \mathrm{ol} .2018 .8160$

\begin{abstract}
Among all malignancies, lung cancer is the leading cause of cancer-related deaths in China. Bone metastasis is one of the most common complications and one of the most important factors affecting the prognosis of lung cancer patients, which resulting in very poor therapeutic effects. Previously, we have demonstrated that the expression levels of Dickkopf1 (DKK1), a protein involved in cell regulation and proliferation, was dramatically higher in cells that have a tendency to metastasize and invade the bone tissue (SBC-5 cells) compared with cells that do not (SBC-3 cells). Downregulation of DKK1 in SBC-5 cells inhibited cell malignancy in vitro, and the formation of bone metastasis in vivo. However, whether upregulating DKK1 would be sufficient to induce aggressive tumor behavior (proliferation, migration, invasion and metastasis) in SBC-3 cells remained to be investigated. The present study aimed to examine the role of DKK1 in SBC-3 cells, as well as to investigate the SBC-3 ability to metastasize and invade the bone tissue. The results demonstrated that upregulation of DKK1 in SBC-3 cells enhanced cell proliferation, colony formation, cell migration and invasion in vitro, as well as bone metastasis in vivo. These results indicate that DKK1 may be an important regulator in the development of small cell lung cancer (SCLC), and targeting DKK1 may be an effective method for preventing and/or treating skeletal metastases in SCLC cases.
\end{abstract}

\section{Introduction}

Lung cancer is the most common cancer in the world, in terms of both morbidity (1.8 million cases, $12.9 \%$ of total) and mortality (1.6 million deaths, $19.4 \%$ of total) (1). Bone is

Correspondence to: Professor Helong Zhang, Department of Oncology, Tangdu Hospital, The Fourth Military Medical University, 569 Xinsi Road, Xi'an, Shaanxi 710038, P.R. China

E-mail: cnxazhl@163.com

*Contributed equally

Key words: Dickkopf1, bone metastasis, small-cell lung cancer one of the most common sites of metastasis in patients with lung cancer, which is often accompanied by skeletal-related events which significantly reduce the quality of life in patients, including bone pain, hypercalcemia, pathological fractures, spinal cord compression and bone marrow infiltration (2-4). Consequently, effective targeted therapies for bone metastasis in lung cancer are urgently needed. However, the mechanisms underlying the development of bone metastasis are not well understood.

Dickkopf1 (DKK1) is known as a negative regulator of the Wnt signaling pathway (5), which regulates cell fate and proliferation. Dysregulation of this pathway has been reported in many developmental defects and cancer (6). Several studies suggest that DKK1 has a role in malignant bone metastasis, such as in breast cancer (6) and prostate cancer $(7,8)$. Previously, a study from our group has demonstrated that the expression levels of DKK1 were significantly higher in SBC-5 cells compared with SBC-3 cells. SBC-5 cells have a greater propensity to metastasize to bone. In addition, downregulation of DKK1 in SBC-5 cells inhibited cell proliferation, colony formation, migration and cell invasion in vitro and bone metastasis in vivo; nevertheless, it also promoted cell apoptosis (9). However, it remained unclear whether upregulating DKK1 in SBC-3 cells could endow them with more aggressive properties, or even reverse their inability to form metastases in the bone. In the present study, DKK1 was overexpressed in SBC-3 cells and consequently it effects were examined in cell proliferation, colony formation, cell migration in vitro, and tumorigenic ability in NOD-SCID mice. The results further confirmed that DKK1, a critical tumor promoter, was associated with skeleton metastasis of SCLC. These data suggested that DKK1 may provide a potential novel strategy for therapeutic intervention in SCLC patients with bone metastases.

\section{Materials and methods}

Cell culture. SBC-5 and SBC-3 cells were a kind gift from Professors Sone and Yano (Tokushima University, Tokushima, Japan). Cells were cultured in RPMI1640 medium (Gibco; Thermo Fisher Scientific, Waltham, MA, USA) supplemented with $10 \%$ fetal bovine serum (FBS; Biochrom GmbH, Berlin, Germany), $100 \mathrm{U} / \mathrm{ml}$ streptomycin and $100 \mathrm{U} / \mathrm{ml}$ penicillin at $37^{\circ} \mathrm{C}$ with $5 \% \mathrm{CO}_{2}$. 
Table I. Primers used in quantitative polymerase chain reaction analysis.

\begin{tabular}{lll}
\hline Gene & \multicolumn{1}{c}{ Forward primer $\left(5^{\prime}-3^{\prime}\right)$} & \multicolumn{1}{c}{ Reverse primer (5'-3') } \\
\hline DKK1 & TAGAGTCTAGAATGCAAGGATCTC & CAAAAACTATCACAGCCTAAAGGG \\
$\beta$-actin & TGGCACCCAGCACAATGAA & CTAAGTCATAGTCCGCCTAGAAGCA \\
\hline
\end{tabular}

DKK1, Dickkopf1.

Reverse transcription-quantitative polymerase chain reaction $(R T-q P C R)$. Total RNA was isolated from cells using TRIzol reagent (Thermo Fisher Scientific, Inc.) following the manufacturer's instructions. Consequently, RNA (500 ng) was reverse-transcribed into cDNA by QuantiNova ${ }^{\mathrm{TM}}$ Reverse Transcription kit (QIAGEN GmbH, Hilden, Germany). qPCR was preformed using SYBR Premix Ex TaqTM II (TakaraBio, Inc., Otsu, Japan), the thermocycling conditions were denaturated at $95^{\circ} \mathrm{C}$ for $30 \mathrm{sec}$, followed by 40 cycles at $95^{\circ} \mathrm{C}$ for $5 \mathrm{sec}$ and $60^{\circ} \mathrm{C}$ for $30 \mathrm{sec}$, real-time fluorescence signals were detected, and gene expression was quantified using $2^{-\Delta \Delta C q}$ method (10). The primer sequences are listed in Table I.

Western blot analysis. The protein of cells was extracted by RIPA buffer (Beyotime Biotechnology, Shanghai, China), after quantification with BCA kit (Pierce, Thermo Fisher Scientific, Inc.), $20 \mu \mathrm{g}$ of protein was subjected to $10 \%$ SDS-PAGE and transferred to nitrocellulose membranes. The members were then blocked in 5\% fat-free milk for $1 \mathrm{~h}$ at room temperature and incubated overnight at $4{ }^{\circ} \mathrm{C}$ with primary antibodies against DKK1 (1:15,00; BS7731; Bioworld Technology, St. Louis Park, MN, USA) or $\beta$-actin $(1: 10,000 ; 051 \mathrm{M} 4892$; Sigma-Aldrich, Merck KGaA, Darmstadt, Germany). Next, peroxidase-conjugated goat anti-rabbit IgG (1:5,000; ZB-2301; Zhongshan, Beijing, China) or peroxidase-conjugated goat anti-mouse IgG (1:5,000; ZB-2305; Zhongshan, Beijing, China) were incubated for $1 \mathrm{~h}$ at room temperature. Finally, the target proteins were visualized by chemiluminescence (Pierce, Thermo Fisher Scientific, Inc.).

Cells stable transfection. DKK1-overexpressing plasmids were obtained from BioworldTechnology, Inc. and 1.2 $\mu \mathrm{g}$ plasmids were transfected into SBC-3 cells in 6-well plates with Lipofectamine 2000 (Invitriogen; Thermo Fisher Scientific, Inc.) according to the manufacturer's instructions. A total of $48 \mathrm{~h}$ after transfection, cells were selected with G418 sulfate $(600 \mu \mathrm{g} / \mathrm{ml})$. One month later, G418-resistant colonies, stably overexpressing DKK1 (termed SBC-3-DKK1 cells), were harvested and consequently subcultured in medium containing $200 \mu \mathrm{g} / \mathrm{ml}$ of G418. Parental SBC-3 cells were used as the control.

MTT assay. Cells in the logarithmic growth phase were harvested and plated in 96-well plates (2,000 cells/well), and cell growth was analyzed for the next days. Briefly, cells were incubated with MTT solution $(5 \mathrm{mg} / \mathrm{ml}, 20 \mu \mathrm{l} /$ well $)$ at $37^{\circ} \mathrm{C}$ for $3 \mathrm{~h}$. Then, the medium was removed and $150 \mu \mathrm{l}$ DMSO was added to dissolve the formazane. The absorbance value was detected at $490 \mathrm{~nm}$ using a microplate reader. The assay was performed in triplicate.

Colony formation assay. Cells in the logarithmic growth phase were harvested and plated in 6 -well plates ( 200 cells/well). Two weeks post-seeding, the cells were stained with $0.25 \%$ crystal violet and the number of colonies was counted manually. The assay was performed in triplicate.

Conditioned medium collection. SBC-5 cells were seeded in 6 -well plate $\left(1 \times 10^{5}\right.$ cells/well). At $24 \mathrm{~h}$ post-seeding, the cells were washed twice with PBS, mixed with serum-free medium, and then incubated for an additional $24 \mathrm{~h}$. Then the conditioned medium $(\mathrm{CM})$ was collected and stored at $-80^{\circ} \mathrm{C}$ for further use.

Cell migration and invasion assay. The invading potential of the cells was investigated using $8-\mu \mathrm{m}$ pore size transwell inserts (Corning Incorporated, Corning, NY, USA). Briefly, cells were first resuspended in serum-free RPMI-1640 and then seeded in triplicates in the upper chamber of the transwells, which was pre-coated with $70 \mu 1$ Matrigel (1:8 dilution; Corning Incorporated). A total of $500 \mu 1$ of RPMI-1640 with $10 \%$ FBS was then added into the bottom chamber to serve as a chemoattractant. To examine the function of DKK1, anti-human DKK1-neutralizing antibody $(10 \mu \mathrm{g} / \mathrm{ml}$; R\&D Systems, Inc., Minneapolis, MN, USA), recombinant human DKK1 $(16 \mu \mathrm{g} / \mathrm{ml}$; PeproTech, NJ, USA), or conditioned medium (CM) were also added to the bottom chambers. Following $24 \mathrm{~h}$ of incubation, cells that invaded to the lower chamber were fixed in $95 \%$ ethyl alcohol and then stained with $0.5 \%$ crystal violet. Finally, the number of invasive cells was counted in five random fields of each sample and the average was determined.

For migration assays, the same protocol was followed, with the only difference being that the inserts were not coated with Matrigel.

In vivo metastasis experiment. A total of 10 female NOD-SCID mice, 4 weeks old, weighing 20-25 g, were obtained from Beijing HFK Bioscience Co. (Beijing, China). Animals were divided into two groups of 5 mice each. SBC-3 cells and SBC-3-DKK1 cells were harvested, resuspended with PBS in a concentration of $5 \times 10^{6} \mathrm{cells} / \mathrm{ml}$ and then injected by tail vein in the mice $(200 \mu \mathrm{l})$. The mice were kept under germ-free conditions (temperature, $22^{\circ} \mathrm{C}$; ventilation rate, $15 / \mathrm{h}$, light/dark cycle, $12 / 12 \mathrm{~h}$; food was sterilized with Cobalt-60 irradiation and water was autoclaved, and access to the food was ad libitum). Five weeks post-injection, mice were anesthetized and the 
A

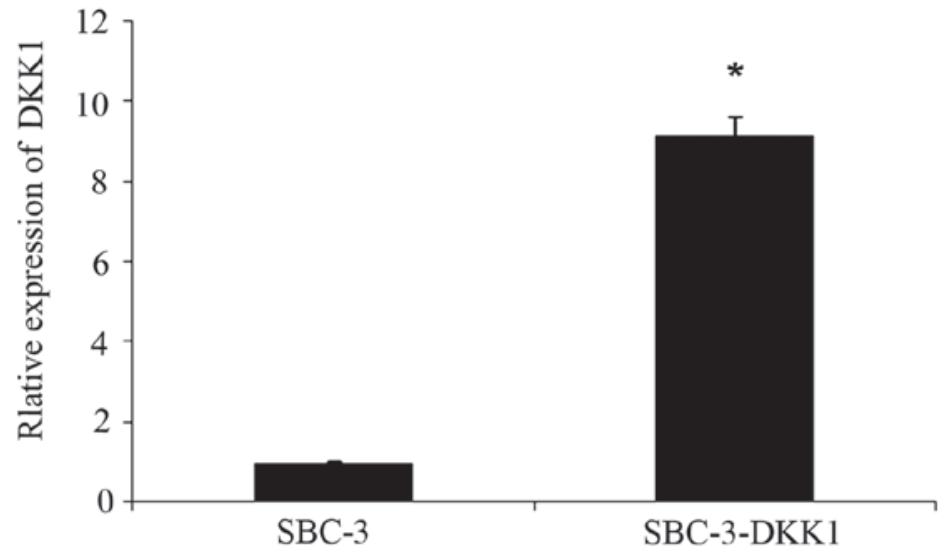

B

DKK1

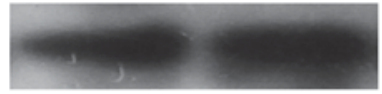

Tubulin
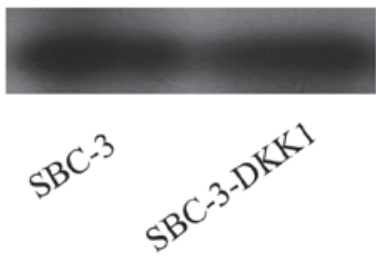

Figure 1. Expression of DKK1 in parental and transfected cells. (A) mRNA levels of DKK1 were measured by reverse transcription-quantitative polymerase chain reaction. (B) Protein expression levels were measured by western blot analysis. "P<0.05. DKK1, Dickkopf1.

A

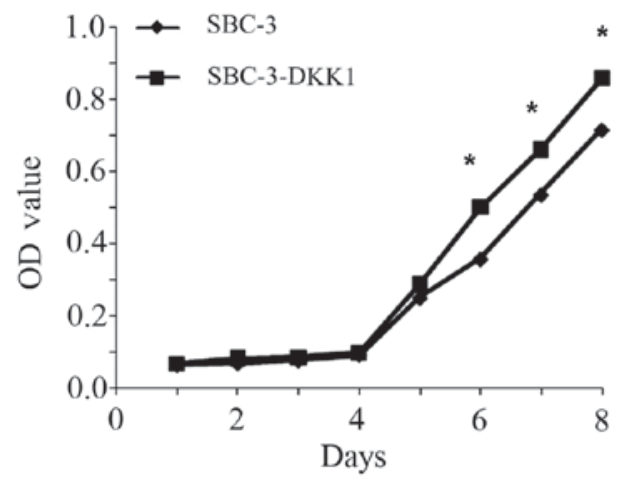

$\mathrm{B}$

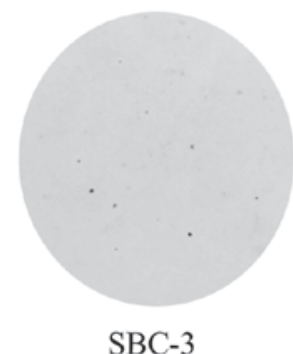

$\mathrm{C}$
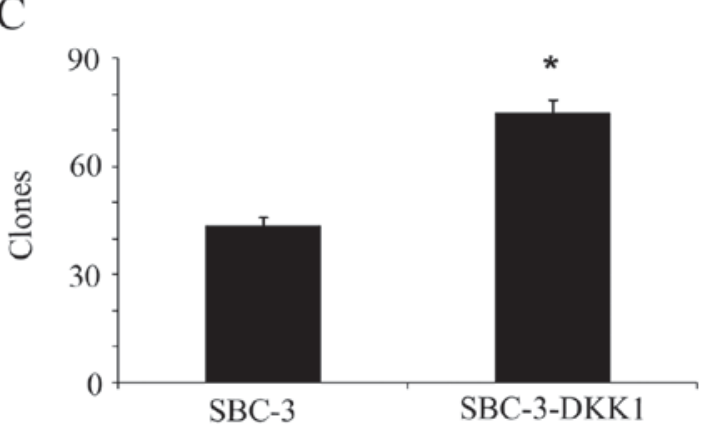

Figure 2. Effect of DKK1 overexpression on the proliferation and colony formation of SBC-3 cells. (A) Cell proliferation curve as determined by MTT assay. ${ }^{*} \mathrm{P}<0.05$. (B) Representative photographs of SBC-3 and SBC-3-DKK1 cell colony formation. (C) Quantification of the colony formation assay. "P<0.05. DKK1, Dickkopf1; OD, optical density.

bone metastases were investigated using an X-ray device. The imaging data of the osteolytic bone metastases were independently evaluated by two experienced investigators.

All animal studies (including the mice euthanasia procedure) were done in compliance with the regulations and guidelines of The Fourth Military Medical University Institutional Animal Care and conducted according to the AAALAC and the IACUC guidelines. The present study was approved by the Animal Experimental Ethical Inspection Committee of The Fourth Military Medical University Laboratory Animal Center (Xi'an, China).

Statistical analysis. One-way analysis of variance was used to analyze the statistical differences in cell migration and invasion assays. The other data was analyzed by t-test. Statistical tests were performed with GraphPad Prism 6 (GraphPad Software, Inc., La Jolla, CA, USA). P $<0.05$ was considered to indicate a statistically significant difference.

\section{Results}

Expression levels of DKK1 were increased in transfected cells. Transfection efficacy of DKK1 in SBC-3 cells was analyzed by RT-qPCR and western blotting. Briefly, DKK1 mRNA (Fig. 1A) and protein (Fig. 1B) expression levels in SBC-3-DKK1 cells were both stably increased compared with parental SBC-3 cells.

Overexpression of DKK1 increases the proliferation ability of SBC-3 cells. The effect of DKK1 overexpression on cell proliferation was tested by MTT and colony formation assays. From the cell growth curve presented in Fig. 2A, it was demonstrated that DKK1 overexpression significantly promoted proliferation of SBC-3 cells compared with the parental SBC-3 cells $(\mathrm{P}<0.05)$. Consistently, by colony formation assay, an increased number of colonies (which were also larger in diameter) were observed in SBC-3-DKK1 cells compared with 
A

B

C

D

E
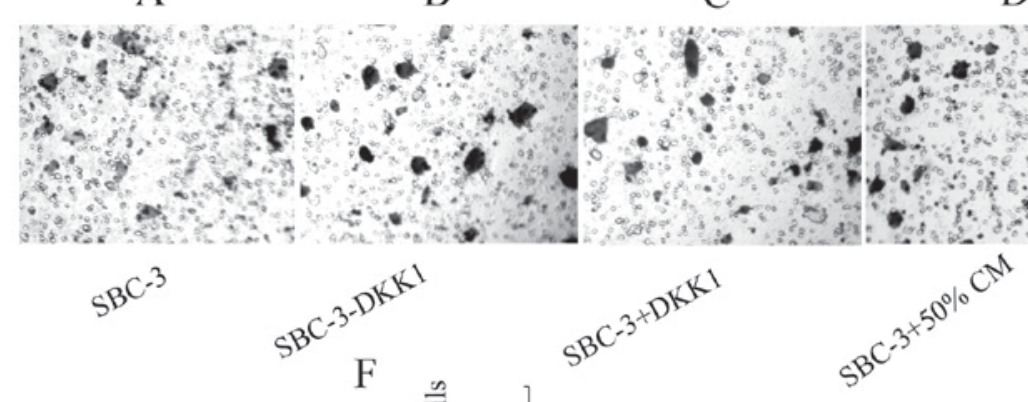

D

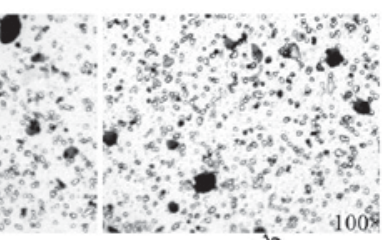

${ }_{S B} \mathrm{C}^{-3}$<smiles>CC(C)C</smiles>

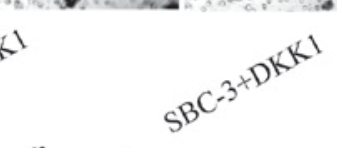

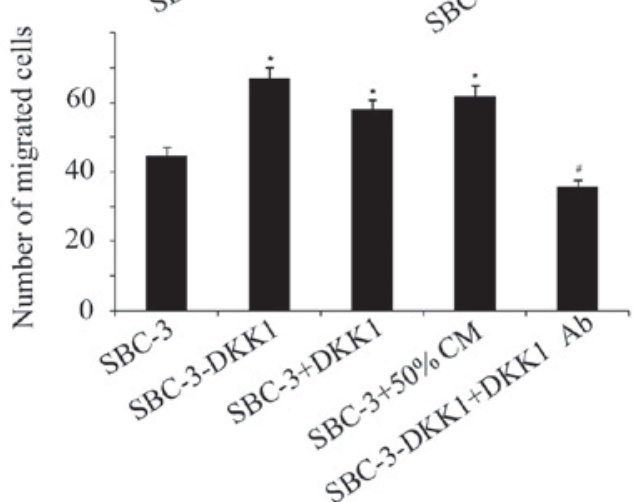

Figure 3. Migration ability of SBC-3-DKK1 and parental SBC-3 cells. Representative images of the stained migrated cells in the (A) parental SBC-3 group, (B) SBC-3-DKK1 group, (C) SBC-3 cells with recombinant human DKK1 in the bottom chamber, (D) SBC-3 cells with 50\% CM and (E) SBC-3-DKK1 cells with a DKK1-neutralizing antibody in the bottom chamber. (F) Quantification of the results from the cell migration assay. Data are expressed as mean \pm standard deviation. " $\mathrm{P}<0.05$ compared with control group and ${ }^{\text {P }}<0.05$ compared with SBC-3-DKK1 group. DKK1, Dickkopf1; CM, conditioned media.

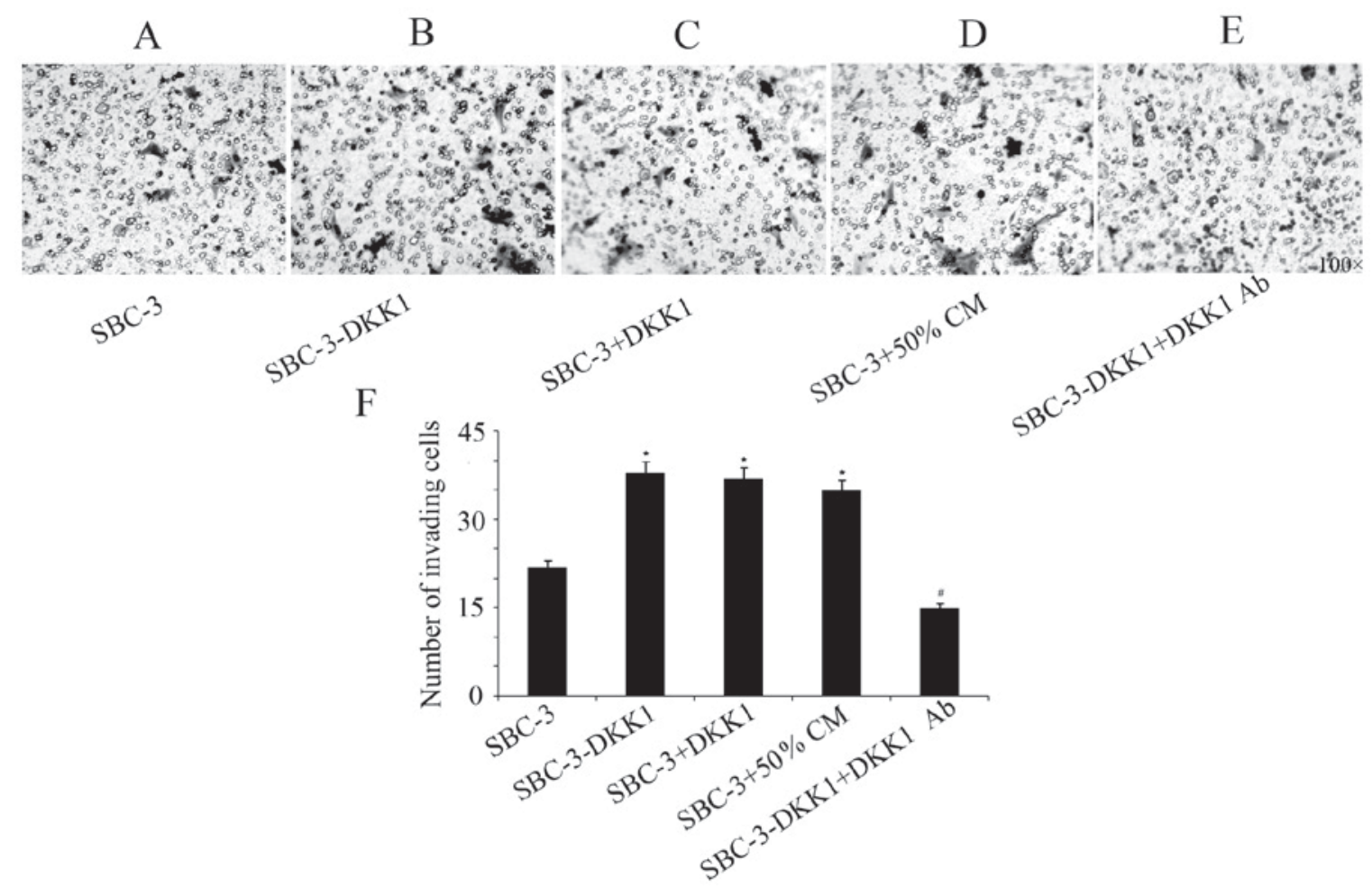

Figure 4. Invasion ability of SBC-3-DKK1 and parental SBC-3 cells. Representative images of the stained invaded cells in the (A) parental SBC-3 group, (B) SBC-3-DKK1 group, (C) SBC-3 cells with recombinant human DKK1 in the bottom chamber, (D) SBC-3 cells with 50\% CM and (E) SBC-3-DKK1 cells with a DKK1-neutralizing antibody in the bottom chamber. (F) Quantification of the results from the cell invasion assay. Data are expressed as mean \pm standard deviation. " $\mathrm{P}<0.05$ compared with control group and ${ }^{*} \mathrm{P}<0.05$ compared with SBC-3-DKK1 group. DKK1, Dickkopf1; CM, conditioned medium.

parental SBC-3 cells ( $\mathrm{P}<0.05$; Fig. 2B and C). To conclude, these results implied that DKK1 acted as a promoter of cell proliferation inSBC-3 cells.
DKK1 overexpression increases migration and invasion in $S B C-3$ cells. Results from the transwell assays indicated that upregulation of DKK1 significantly increased the invasive 
Table II. Incidence of bone metastasis and the number of metastasis lesions formed in NOD-SCID mice.

\begin{tabular}{lcc}
\hline Cell line & Incidence & Numbers of bone metastases \\
\hline SBC-3 & $0 / 5$ & $0.00 \pm 0.00$ \\
SBC-3-DKK1 & $3 / 5$ & $1.40 \pm 1.34^{\mathrm{a}}$ \\
\hline
\end{tabular}

${ }^{\mathrm{a}} \mathrm{P}=0.048$ compared with the control group. DKK1, Dickkopf 1 .

and migratory capabilities of SBC-3 cells (Figs. 3 and 4). Furthermore, addition of recombinant DKK1 or CM from SBC-5 cells had the same effect in increasing migration and invasion of SBC-3 cells (Figs. 3 and 4). By contrast, addition of the DKK1-neutralizing antibody in the SBC-3-DKK1 cells reversed the effect of DKK1 overexpression on cell invasion and migration (Figs. 3 and 4).

Overexpression of DKK1 facilitates bone metastasis in vivo. $\mathrm{X}$-ray imaging was used to investigate whether overexpression of DKK1 had an effect on in vivo metastasis. As presented in Table II, bone metastasis was observed in 3 of 5 mice in the SBC-3-DKK1 group, while no metastasis (0/5) was detected in the control SBC-3 group. Furthermore, the total number of bone metastasis lesions was counted (Table II). The results suggested that upregulation of DKK1 could enhance metastasis to bone. Representative X-ray images of skeletal metastasis are shown in Fig. 5.

\section{Discussion}

DKK1, a secreted inhibitor of the Wnt/ $\beta$-catenin pathway, is a member of the human DKK family. Many of these extensively studied members have been evolutionarily conserved and include an intricate network of signaling molecules known to participate in bone diseases, Alzheimer's disease and cancer (11-15). Several reports associate DKK1 expression with skeletal lesions. DKK1 has a promoting role in the formation of bone lesions in patients with multiple myeloma $(16,17)$, since DKK1 can prohibit osteoblastic differentiation. Consistently, elevated circulating DKK-1 levels in patients with multiple myeloma have been associated with osteolytic lesions $(18,19)$. Furthermore, DKK1 is expressed at a higher level the MDA-MB-231-BO breast cancer cell line, which metastasizes exclusively to bone and produces larger osteolytic lesions compared to the parental MDA-MB-231 line. This advanced malignant feature is caused by inhibition in osteoblast differentiation and osteoprotegerin expression $(6,20)$. In addition, DKK1 overexpression significantly increases the subcutaneous tumor volumes and the incidence of bone metastases of the after intracardiac Ace-1 prostate cancer cells (8). It is speculated that DKK1 may reduce the Ace-1 osteoblastic phenotype, resulting in increased phospho-46 c-Jun N-terminal kinase via the Wnt noncanonical pathway (8). A lung cancer study reported that the serum levels of DKK1 in patients with bone metastases were higher compared with NSCLC patients without bone metastasis, suggesting that DKK1 secreted by lung cancer cells may be associated with NSCLC bone metastasis (21).
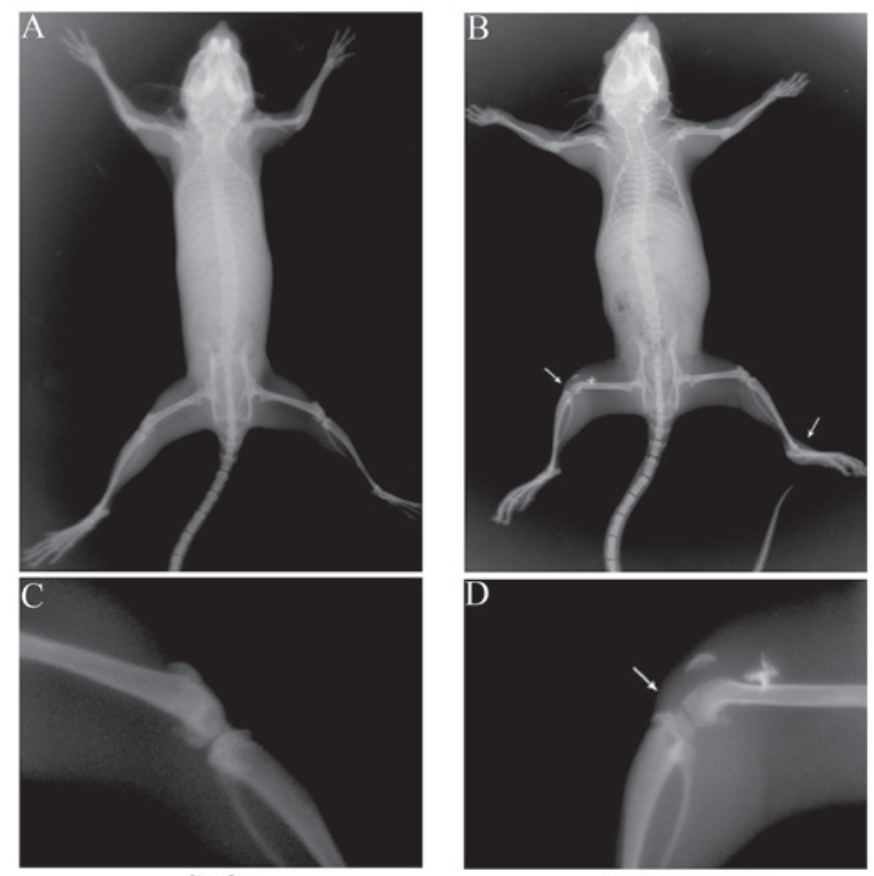

SBC-3

SBC-3-DKK 1

Figure 5. X-ray images of osteolytic bone metastases in mice. Representative whole body imaging of (A) the SBC-3 group, and (B) the SBC-3-DKK1 group. A higher resolution image of the bone lesions is shown for the SBC-3 and the SBC-3-DKK1 group in (C) and (D), respectively. Metastatic lesions are denoted by arrows. DKK1, Dickkopf1.

A previous study from our group has demonstrated that downregulation of DKK1 in bone-metastatic SCLC cells (SBC-5) could partially inhibit cell proliferation, colony formation, migration and invasion in vitro, and bone metastases in vivo (9). In the present study, DKK1 expression was upregulated in SBC-3 cells, which have inherently low expression levels of DKK1 and no tendency to metastasize to bone tissue. The obtained results indicated that overexpression of DKK1 in SBC-3 cells was sufficient to enhance their capacity of proliferation, colony formation, migration and invasion in vitro, as well as their bone metastasis potential in vivo. In conclusion, DKK1 was demonstrated to be involved in the skeletal metastasis of SCLC cells. Furthermore, DKK1 was identified as an indispensable tumor contributor for the development of bone metastases, and therefore, it may serve as a promising target for the prevention and effective treatment of bone metastases in SCLC. Further studies will be needed in the future in order to fully elucidate the molecular mechanisms underlying the role of DKK1 on bone metastasis of lung cancer.

\section{Acknowledgements}

Not applicable.

\section{Funding}

The present study was supported by the National Natural Science Foundation of China (grant nos. 81572251 and 81402411) and the Natural Science Foundation of Shanxi, China (grant no. 2016JM8036). 


\section{Availability of data and materials}

The analyzed datasets generated during the study are available from the corresponding author on reasonable request.

\section{Authors' contributions}

HP constructed stable transected cell lines and collated data. NM detected cells proliferation, colony formation and cell migration. WS was a major contributor in writing the manuscript. QZ performed the cell invasion in vitro. WC, JW and LD performed the mice experiments. NZ and ZZ were responsible for the $\mathrm{X}$-ray device and evaluated osteolytic bone metastases. LL and HZ guided and reviewed the experiments. All authors read and approved the final manuscript.

\section{Ethics approval and consent to participate}

The present study was approved by the Animal Experimental Ethical Inspection Committee of The Fourth Military Medical University Laboratory Animal Center (Xi'an, China).

\section{Consent for publication}

Not applicable.

\section{Competing interests}

The authors declare that they have no competing interests.

\section{References}

1. Ferlay J, Soerjomataram I, Dikshit R, Eser S, Mathers C, Rebelo M, Parkin DM, Forman D and Bray F: Cancer incidence and mortality worldwide: Sources, methods and major patterns in GLOBOCAN 2012. Int J Cancer 136: E359-E386, 2015.

2. Oster G, Lamerato L, Glass AG, Richert-Boe KE, Lopez A, Chung K, Richhariya A, Dodge T, Wolff GG, Balakumaran A and Edelsberg J: Natural history of skeletal-related events in patients with breast, lung, or prostate cancer and metastases to bone: A 15-year study in two large US health systems. Support Care Cancer 21: 3279-3286, 2013.

3. Silva SC, Wilson C and Woll PJ: Bone-targeted agents in the treatment of lung cancer. Ther Adv Med Oncol 7: 219-228, 2015.

4. Roato I: Bone metastases: When and how lung cancer interacts with bone. World J Clin Oncol 5: 149-155, 2014.

5. Menezes ME, Devine DJ, Shevde LA and Samant RS: Dickkopf1: A tumor suppressor or metastasis promoter? Int J Cancer 130: 1477-1483, 2012.

6. Bu G, Lu W, Liu CC, Selander K, Yoneda T, Hall C, Keller ET and Li Y: Breast cancer-derived Dickkopf1 inhibits osteoblast differentiation and osteoprotegerin expression: Implication for breast cancer osteolytic bone metastases. Int J Cancer 123: 1034-1042, 2008.
7. Hall CL, Daignault SD, Shah RB, Pienta KJ and Keller ET: Dickkopf-1 expression increases early in prostate cancer development and decreases during progression from primary tumor to metastasis. Prostate 68: 1396-1404, 2008.

8. Thudi NK, Martin CK, Murahari S, Shu ST, Lanigan LG, Werbeck JL, Keller ET, McCauley LK, Pinzone JJ and Rosol TJ: Dickkopf-1 (DKK-1) stimulated prostate cancer growth and metastasis and inhibited bone formation in osteoblastic bone metastases. Prostate 71: 615-625, 2011.

9. Pang H, Ma N, Jiao M, Shen W, Xin B, Wang T, Zhang F, Liu L and Zhang $\mathrm{H}$ : The biological effects of Dickkopf1 on small cell lung cancer cells and bone metastasis. Oncol Res 25: 35-42, 2017.

10. Livak KJ and Schmittgen TD: Analysis of relative gene expression data using real-time quantitative PCR and the 2(-Delta Delta C(T)) method. Methods 25: 402-408, 2001.

11. Cadigan KM and Nusse R: Wnt signaling: A common theme in animal development. Genes Dev 11: 3286-3305, 1997.

12. Krupnik VE, Sharp JD, Jiang C, Robison K, Chickering TW, Amaravadi L, Brown DE, Guyot D, Mays G, Leiby K, et al: Functional and structural diversity of the human Dickkopf gene family. Gene 238: 301-313, 1999.

13. Moon RT, Kohn AD, De Ferrari GV and Kaykas A: WNT and beta-catenin signalling: Diseases and therapies. Nat Rev Genet 5: 691-701, 2004.

14. MacDonald BT, Tamai $\mathrm{K}$ and $\mathrm{He} \mathrm{X}$ : Wnt/beta-catenin signaling: Components, mechanisms, and diseases. Dev Cell 17: 9-26, 2009.

15. Rao TP and Kühl M: An updated overview on Wnt signaling pathways: A prelude for more. Circ Res 106: 1798-1806, 2010.

16. Tian E, Zhan F, Walker R, Rasmussen E, Ma Y, Barlogie B and Shaughnessy JD Jr: The role of the Wnt-signaling antagonist DKK1 in the development of osteolytic lesions in multiple myeloma. N Engl J Med 349: 2483-2494, 2003.

17. Politou MC, Heath DJ, Rahemtulla A, Szydlo R, Anagnostopoulos A, Dimopoulos MA, Croucher PI and Terpos E: Serum concentrations of Dickkopf-1 protein are increased in patients with multiple myeloma and reduced after autologous stem cell transplantation. Int J Cancer 119: 1728-1731, 2006.

18. Pinzone JJ, Hall BM, Thudi NK, Vonau M, Qiang YW, Rosol TJ and Shaughnessy JD Jr: The role of Dickkopf-1 in bone development, homeostasis, and disease. Blood 113: 517-525, 2009.

19. Giuliani N and Rizzoli V: Myeloma cells and bone marrow osteoblast interactions: Role in the development of osteolytic lesions in multiple myeloma. Leuk Lymphoma 48: 2323-2329, 2007.

20. Yoneda T, Williams PJ, Hiraga T, Niewolna M and Nishimura R: A bone-seeking clone exhibits different biological properties from the MDA-MB-231 parental human breast cancer cells and a brain-seeking clone in vivo and in vitro. J Bone Miner Res 16: 1486-1495, 2001.

21. Chu T, Teng J, Jiang L, Zhong H and Han B: Lung cancer-derived Dickkopf1 is associated with bone metastasis and the mechanism involves the inhibition of osteoblast differentiation. Biochem Biophys Res Commun 443: 962-968, 2014. 